\title{
Genetic and Morphological Diversity of Temperate and Tropical Isolates of Phytophthora capsici
}

\author{
J. H. Bowers, F. N. Martin, P. W. Tooley, and E. D. M. N. Luz
}

First author: U.S. Department of Agriculture- Agricultural Research Service (USDA- ARS), Alternate Crops \& Systems Lab., Beltsville, MD 20705; second author: USDA-ARS, Crop Improvement \& Protection Research Unit, Salinas, CA 93905; third author: USDA-ARS, Foreign Disease-Weed Science Research Unit, Ft. Detrick, MD 21702; and fourth author: CEPLAC, Seção de Fitopatologia, Itabuna, Brazil.

Current address of J. H. Bowers: Maryland Department of Agriculture, Plant Protection and Weed Management, Annapolis 21401.

Accepted for publication 24 October 2006.

\begin{abstract}
Bowers, J. H., Martin, F. N., Tooley, P. W., and Luz, E. D. M. N. 2007. Genetic and morphological diversity of temperate and tropical isolates of Phytophthora capsici. Phytopathology 97:492-503.

Phytophthora capsici is a diverse species causing disease on a broad range of both temperate and tropical plants. In this study, we used cultural characteristics, amplified fragment length polymorphism (AFLP), and DNA sequence analyses of the ribosomal internal transcribed spacer (ITS) region and mitochondrial cytochrome oxidase II (cox II) genes to characterize temperate and tropical isolates from a wide range of host species. All but one temperate isolate grew at $35^{\circ} \mathrm{C}$, while all tropical isolates did not. All but two tropical isolates formed chlamydospores, while temperate isolates did not. There was strong bootstrap support for separation of temperate and tropical isolates using AFLP analysis; however, the temperate isolates appeared as a subgroup within the observed variation of the tropical isolates. The majority of temperate isolates clustered within a single clade with low variation regardless of host or geographical origin, while the tropical isolates were more variable and grouped into three distinct clades. Two clades of tropical isolates grouped

between the temperate and tropical isolates as with the AFLP results. Sequence divergence among isolates and clades was low, with more variation within the tropical isolates than within the temperate isolates. Analysis of other species revealed shorter branch lengths separating temperate and tropical isolates than were observed in comparisons among other phylogenetically closely related species in the genus. Analysis of cox II sequence data was less clear. Although the temperate and tropical isolates grouped together apart from other species, there was no bootstrap support for separating these isolates. Restriction fragment length polymorphism (RFLP) analysis of the ITS regions separated the temperate and tropical isolates, as in the AFLP and ITS phylogenetic analyses. However, RFLP analysis of the cox I and II gene cluster did not distinguish between temperate and tropical isolates. The differences in grouping of isolates in these two RFLP studies should be helpful in identifying isolate subgroups. Our data do not fully clarify whether or not temperate and tropical isolates should be separated into different species. The available worldwide data are incomplete and the full range of variation in the species is not yet known. We suggest refraining from using the epithet $P$. tropicalis until more data are available.
\end{abstract} together and were affiliated closely with the temperate isolates, while the third tropical clade was more distantly related. Phylogenetic analysis of the ITS regions resulted in similar groupings and variation within and
Additional keywords: phylogeny.
Phytophthora capsici Leonian was first described in 1922 on Capsicum annuum L. (chili pepper) in New Mexico (29). Originally, this pathogen was considered to be host specific (44), but since has been reported as a devastating pathogen on bell pepper, squash, pumpkin, tomato, and other temperate solanaceous and cucurbit hosts worldwide $(13,28,40)$. This fungal-like pathogen also has been reported to cause disease on a variety of tropical hosts, including cacao, rubber, macadamia, papaya, black pepper, and others (13). P. capsici causes root and crown rots, as well as stem, leaf, and fruit lesions (40). The pathogen is heterothallic and requires both $\mathrm{A} 1$ and $\mathrm{A} 2$ compatibility types for sexual reproduction. Both compatibility types are common in the same fields, and have been found within the same plant $(25,39)$. P. capsici forms papillate sporangia that are borne on long pedicels and are caducous (13).

Chlamydospores are rare in cultures of isolates from solanaceous or cucurbit hosts, but are reported to be abundant in cultures of isolates from black pepper, cacao, and macadamia $(1,13,39,44,45)$.

Corresponding author: J. H. Bowers; E-mail address: BowersJH@mda.state.md.us

doi:10.1094/PHYTO-97-4-0492

This article is in the public domain and not copyrightable. It may be freely reprinted with customary crediting of the source. The American Phytopathological Society, 2007.
Previously, all isolates of Phytophthora from cacao were classified as P. palmivora (Butl.) Butler (7). However in 1976, isolates of $P$. palmivora from cacao were placed into one of four morphological groups (MF1, MF2, MF3, and MF4) (17). After further study, the MF4 form was considered to be $P$. capsici Leonian (13, 43,48). MF4 isolates from cacao, black pepper, and other tropical crops, some of which formed chlamydospores, were characterized as $P$. capsici in an amended description of the species (43).

It was suggested that isolates that are pathogenic to tropical crops, avirulent to pepper, and that produce chlamydospores are distinct from $P$. capsici $(3,46)$. Oudemans and Coffey (37), using isozyme analysis, separated isolates of $P$. capsici into three subgroups: CAP1, CAP2, and CAP3. Isolates determined to be distinct from $P$. capsici fell within both CAP2 and CAP3 (46). An expanded isozyme analysis by Mchau and Coffey (36) using 15 enzymes separated 113 isolates of $P$. capsici into two subgroups, CapA and $\mathrm{CapB}$, but each subgroup contained isolates from a wide range of hosts and geographical locations, and members of each group varied in morphology. P. capsici was broadly redefined based on additional isozyme data and the wide range of morphological attributes found in a worldwide collection (36). Nevertheless, there have been continued reports that there exists considerable diversity in host-specific pathogenicity $(4,39,46)$ and genetic variability among and within populations of $P$. capsici (26). 
In a study to re-examine the species, Aragaki and Uchida (4) compared morphological attributes of over 100 isolates of $P$. capsici with deciduous, long-pedicellate sporangia. The isolates were separable into two groups: $P$. capsici and a proposed new species, $P$. tropicalis sp. nov. The proposed new species would include those isolates that morphologically differ from $P$. capsici by having narrow sporangia (less than $26 \mu \mathrm{m}$ in diameter), a sporangial length-to-breadth ratio of 1.8 or more, predominantly tapered sporangial bases, production of chlamydospores, poor or no growth at $35^{\circ} \mathrm{C}$, and weak or no pathogenicity on pepper. In a molecular sequence study with a limited number of isolates, Zhang et al. (49) reported that the internal transcribed spacer (ITS) ITS1 and ITS2 rDNA regions (with the 18S, 5.8S, and 28S subgroups removed) of $P$. capsici and isolates referred to as $P$. tropicalis were the same size but had 21 nucleotide substitutions between the two groups. At some sites, only one of the four P. tropicalis isolates differed from the two $P$. capsici isolates, while at other sites, all four P. tropicalis isolates differed from P. capsici. These differences, however, were fewer than the differences between the $P$. capsicilP. tropicalis group and either P. palmivora or P. nicotianae, and fewer than the differences between $P$. palmivora and $P$. nicotianae. Isolates of $P$. tropicalis were genetically more variable than isolates of $P$. capsici. Zhang et al. (49) concluded that their results support the separation of $P$. tropicalis as a distinct species. However, are the differences reported within this group of isolates, as opposed to the differences among other species, enough to support a new species given that what was studied was only a small number of isolates and a small region of the genome? Kong et al. (24) also reported a separation of isolates of $P$. capsici and $P$. tropicalis using single-strand-conformation polymorphisms (SSCP) of the ITS1 rDNA region. However, only four isolates of $P$. capsici and one isolate of $P$. tropicalis were included in the study. The variation within and between the species was not presented, and it is not known whether or not a continuum or a delimitation of responses exists among this group of isolates using this methodology.

It is important to know whether morphologically similar isolates of a described species from diverse hosts represent one worldwide population, or if these isolates represent an assemblage of cryptic species occurring with hosts and climate. The genetic differences among isolates of a species are very important to those designing breeding programs for disease resistance. Thus, the characterization of pathogen isolates used as challenge inoculum and their relation to field populations of the species in question is critical. Likewise, in a biological control approach, biological control agents often are highly specific for target populations $(6,23)$. Thus, it is very important to know if isolates from different climates or hosts are similar or different based on genetic, morphologic, or pathogenetic criteria, or if their relationship is based on a combination of any of these criteria. Will disease resistance or control methodology developed for one population be applicable to similar populations?

Here we report the characterization of isolates of $P$. capsici and $P$. tropicalis across numerous host plants, geographical regions, and climates, using morphological and multigene approaches. Amplified restriction fragment length polymorphism (AFLP) analysis was used to assess the genetic variation at the species level. Sequencing data of one nuclear locus, ribosomal DNA internal transcribed spacer regions (ITS) (9), and one mitochondrial locus, cytochrome oxidase II (cox II) gene (33), were used to investigate molecular phylogenetic relationships of these isolates with closely related taxa. Restriction fragment length polymorphism (RFLP) analysis of these two loci also was done to provide additional comparison with other members of the genus $(11,34)$. The data were used to determine if subgroups within the species exhibit enough genetic distance to lead us to recognize these subgroups as two different taxa.

\section{MATERIALS AND METHODS}

Phytophthora cultures. Isolates of $P$. capsici and $P$. tropicalis used in this study are listed in Table 1 . Isolates were maintained on $5 \%$ clarified V8-juice (CV8) agar medium (5) in the dark at 12 to $14^{\circ} \mathrm{C}$ and on $0.5-\mathrm{cm}^{2}$ pieces of $\mathrm{CV} 8$ agar medium in small glass bottles with sterile distilled water and a sterile hemp seed at room temperature. Radial growth of the isolates was assessed as described by Aragaki and Uchida (4). Radial growth experiments were performed twice with two replications per isolate in each experiment. Data were analyzed using the SAS statistical package (SAS Inst., Cary, NC). Chlamydospore production was assessed using the submerged culture method $(42,45)$.

DNA extraction. Cultures from storage were transferred to fresh CV8 agar medium and grown in the dark at 22 to $24^{\circ} \mathrm{C}$ for 3 to 5 days. Agar plugs were taken from the colony margins and inoculated into $40 \mathrm{ml}$ of $10 \% \mathrm{CV} 8$ broth medium in a $250-\mathrm{ml}$ flask. Stationary broth cultures were incubated as above for 7 to 10 days. Mycelial mats were harvested by washing with sterile distilled water, were dried on filter paper with a vacuum, placed in a sterile, disposable centrifuge tube, frozen at $-20^{\circ} \mathrm{C}$ overnight, and then lyophilized. Approximately $20 \mathrm{mg}$ of lyophilized mycelium was transferred to a sterile microcentrifuge tube and ground with a micropestle. Genomic DNA was extracted using the DNeasy Plant Mini Kit (Qiagen, Valencia, CA) following the manufacturer's instructions and then quantified using a Fluoroskan Ascent and Ascent software version 2.4 (Thermo Electron Corp., Waltham, MA) with the PicoGreen dsDNA Quantification Kit (Molecular Probes, Eugene, OR).

AFLP analysis. AFLP analysis was carried out using the AFLP Microbial Fingerprinting Kit in accordance with the manufacturer's instructions (Applied Biosystems, Foster City, CA). The restriction-ligation reaction for each sample was carried out overnight at room temperature in a total volume of $11 \mu \mathrm{l}$, with approximately $100 \mathrm{ng}$ of genomic DNA resuspended in $5.5 \mu \mathrm{l}$ of sterile distilled water and $5.5 \mu \mathrm{l}$ of an enzyme master mix in accordance with manufacturer's instructions. EcoRI and MseI enzymes and associated buffers not in the AFLP kit were obtained from New England BioLabs (Beverly, MA).

The restriction-ligation reaction products were diluted 1:19 in $0.1 \%$ Tris-EDTA (TE) buffer, and stored at $4{ }^{\circ} \mathrm{C}$. Preselective amplification was performed on $4.0 \mu \mathrm{l}$ of diluted restriction-ligation reaction and $16.0 \mu \mathrm{l}$ of an AFLP Amplification Core Mix with preselective primers (core sequences) EcoRI (5'-GACTGCGTACCAATTC- $3^{\prime}$ ) and $M s e I$ (5'-GATGAGTCCTGAGTAA-3'). Preselective amplification was carried out in a Gene Amp polymerase chain reaction (PCR) System 9700 (Applied Biosystems) with the temperature cycling program described in the AFLP protocol. PCR products were diluted 1:20 in 0.1\% TE buffer and stored at $4^{\circ} \mathrm{C}$. The selective amplification procedure was modified slightly from the AFLP protocol. The selective amplification master mix consisted of $7.5 \mu \mathrm{l}$ of AFLP Amplification Core mix, $0.75 \mu \mathrm{l}$ of $1.0 \mu \mathrm{M} E c o$ RI dye-labeled primer, and $0.75 \mu \mathrm{l}$ of $5.0 \mu \mathrm{M} \mathrm{MseI}$ primer. Nine microliters of the selective amplification master mix was mixed with $1.0 \mu \mathrm{l}$ of diluted preselective amplification products. The selective amplification EcoRI primers had an additional two- nucleotide extension at the $3^{\prime}$ end (-AG, -AC, -AT, and -AA) and were labeled at the $5^{\prime}$ end with a fluorescent WellRED D4-PA dye-labeled phosphoramidite (Invitrogen). The selective amplification MseI primer had an additional nucleotide extension on the $3^{\prime}$ end (-C). Selective amplifications were carried out using a combination of each modified EcoRI primer with MseI-C using the temperature cycling program given in the original AFLP protocol. Selective amplification products were diluted 30-fold in Sample Loading Solution (Beckman Coulter, Fullerton, CA), which included Beckman Coulter 400-bp DNA size standards. Fragments were separated and detected using capillary electrophoresis on the CEQ 8000 Genetic Analysis System (Beckman 
Coulter, Inc.). Fragment data were analyzed using the CEQ 8000 Fragment Analysis Software (version 6.0) with parameters that recognized peaks exceeding a height threshold of $10 \%$ of the height of the second largest peak and a slope threshold of 10. The bin (peak) width was adjusted to 1.0. The automated scoring was examined and manually adjusted if necessary. Samples were scored for each bin as a " 1 " if a fragment of that size was present, and as a " 0 " if a fragment of that size was not present. All bins scored were polymorphic and were included in the analysis. Data were imported into the freeware program FreeTree, version 0.9.1.50 $(12,18)$. A similarity matrix was generated using Jaccard's similarity coefficient, and cluster analysis was performed using the unweightedpair group method with arithmetic mean algorithm (UPGMA) and bootstrap analysis with 1,000 resamplings. Clades with bootstrap values above $70 \%$ were considered strongly supported by the data. Trees were visualized using TreeView, version 1.6.6 (38).

Amplification and sequencing of the ITS regions. The ribosomal DNA region containing the ITS regions ITS1 and 2, and the
5.8S rRNA gene, was amplified with the universal primers ITS6 (forward) (5'-GAAGGTGAAGTCGTAACAAGG-3') and ITS4 (reverse) (5'-TCCTCCGCTTATTGATATGC-3') (9,10,47). PCR Reaction mixture contained 1X Platinum PCR Super Mix (Invitrogen), $0.4 \mu \mathrm{M}$ each of primers ITS6 and ITS4 (Invitrogen), and $1 \mu \mathrm{l}$ of genomic DNA for a total volume of $50 \mu \mathrm{l}$. Amplifications were done in the Gene Amp PCR System 9700 with cycling conditions as follows: $94^{\circ} \mathrm{C}$ for $2 \mathrm{~min}, 35$ cycles of $94^{\circ} \mathrm{C}$ for $30 \mathrm{~s}$, $55^{\circ} \mathrm{C}$ for $30 \mathrm{~s}$, and $72^{\circ} \mathrm{C}$ for $1 \mathrm{~min}$. Reaction products were purified using QIAquick PCR Purification Kit (Qiagen) as per manufacturer's instructions, using $50 \mu \mathrm{l}$ of that kit's Buffer EB, and then placing the final product in a heating block at $55^{\circ} \mathrm{C}$ for 3 to 5 min to remove traces of residual ethanol. The PCR products were diluted 1:25 in Buffer EB and then DNA concentration was determined by UV absorbance using a spectrophotometer. Each sample was diluted to $20 \mathrm{ng} / \mu \mathrm{l}$ and the primers diluted to $0.8 \rho \mathrm{M}$. The sample DNA was sequenced at the University of Maryland DNA Sequencing Facility, Center for Biosystems Research (College

TABLE 1. Isolates of Phytophthora capsici and P. tropicalis used in this study

\begin{tabular}{|c|c|c|c|c|c|c|c|}
\hline Isolate $^{\mathrm{a}}$ & Host & & Origin & Environment & Source ${ }^{b}$ & GenBank - ITS ${ }^{c}$ & GenBank - cox II \\
\hline R198 & Bell pepper & Capsicum annuиm $\mathrm{L}$. & New Jersey & Temperate & S. A. Johnston & DQ464018 & $--^{d}$ \\
\hline R499 & Eggplant & Solanum melongena $\mathrm{L}$. & New Jersey & Temperate & S. A. Johnston & DQ464019 & -- \\
\hline R599 & Bell pepper & Capsicum anпиит $\mathrm{L}$. & New Jersey & Temperate & S. A. Johnston & DQ464020 & -- \\
\hline R699 & Tomato & Lycopersicon esculentum Mill. & New Jersey & Temperate & S. A. Johnston & DQ464021 & DQ469719 \\
\hline R899 & Bell pepper & Capsicum aпnиит $\mathrm{L}$. & New Jersey & Temperate & S. A. Johnston & DQ464022 & -- \\
\hline R998 & Bell pepper & Capsicum annuиm $\mathrm{L}$. & New Jersey & Temperate & S. A. Johnston & DQ464023 & -- \\
\hline R1098-1 & Bell pepper & Capsicum annuиm $\mathrm{L}$. & New Jersey & Temperate & S. A. Johnston & DQ464024 & -- \\
\hline R1099 & Yellow squash & Cucurbita pepo L. & New Jersey & Temperate & S. A. Johnston & DQ464025 & -- \\
\hline $\mathrm{R} 1198$ & Bell pepper & Capsicum annuum $\mathrm{L}$. & New Jersey & Temperate & S. A. Johnston & DQ464026 & DQ469720 \\
\hline $\mathrm{R} 1298$ & Bell pepper & Capsicum annиum $\mathrm{L}$. & New Jersey & Temperate & S. A. Johnston & DQ464027 & DQ469721 \\
\hline 219 & Bell pepper & Capsicum annuиm $\mathrm{L}$. & New Jersey & Temperate & S. A. Johnston & DQ464028 & -- \\
\hline 220 & Eggplant & Solanum melongena $\mathrm{L}$. & New Jersey & Temperate & S. A. Johnston & DQ464029 & DQ469722 \\
\hline 223 & Bell pepper & Capsicum anпиит $\mathrm{L}$. & New Jersey & Temperate & S. A. Johnston & DQ464030 & -- \\
\hline 224 & Bell pepper & Capsicum anпиит $\mathrm{L}$. & New Jersey & Temperate & S. A. Johnston & DQ464031 & -- \\
\hline 230 & Tomato & Lycopersicon esculentum Mill. & New Jersey & Temperate & S. A. Johnston & DQ464032 & -- \\
\hline RA1 & Eggplant & Solanum melongena L. & New Jersey & Temperate & S. A. Johnston & -- & DQ469724 \\
\hline RA4 & Bell pepper & Capsicum annuum $\mathrm{L}$. & New Jersey & Temperate & S. A. Johnston & DQ464033 & DQ469723 \\
\hline RA16 & Bell pepper & Capsicum annuиm $\mathrm{L}$. & New Jersey & Temperate & S. A. Johnston & DQ464034 & -- \\
\hline 23 & Bell pepper & Capsicum annuum $\mathrm{L}$. & North Carolina & Temperate & J. A. Ristaino & DQ464035 & -- \\
\hline B2HH4 & Bell pepper & Capsicum annиum $\mathrm{L}$. & North Carolina & Temperate & J. A. Ristaino & DQ464036 & DQ469725 \\
\hline $\mathrm{Cp}-1$ & Cacao & Theobroma cacao $\mathrm{L}$. & Brazil & Tropical & D. J. Mitchell & DQ464037 & DQ469726 \\
\hline $\mathrm{Cp}-2$ & Black pepper & Piper nigrum L. & Puerto Rico & Tropical & D. J. Mitchell & DQ464038 & DQ469727 \\
\hline Cp-16 & Bell pepper & Capsicum annuиm $\mathrm{L}$. & Florida & Temperate & D. J. Mitchell & DQ464039 & -- \\
\hline $\mathrm{Cp}-17$ & Bell pepper & Capsicum anпиит $\mathrm{L}$. & Florida & temperate & D. J. Mitchell & DQ464040 & -- \\
\hline $\mathrm{Cp}-30$ & Bell pepper & Capsicum aппиит $\mathrm{L}$. & Florida & Temperate & D. J. Mitchell & DQ464041 & -- \\
\hline $\mathrm{Cp}-32$ & Bell pepper & Capsicum anпиит $\mathrm{L}$. & Florida & Temperate & D. J. Mitchell & DQ464042 & -- \\
\hline Cp-D1 & Lima bean & Phaseolus lunatus L. & Delaware & Temperate & C. Davidson & DQ464043 & -- \\
\hline $\mathrm{Cp}-\mathrm{D} 2$ & Lima bean & Phaseolus lunatus L. & Maryland & Temperate & C. Davidson & DQ464044 & DQ469728 \\
\hline Cp-D3 & Lima bean & Phaseolus lunatus L. & Maryland & Temperate & C. Davidson & DQ464045 & DQ469729 \\
\hline Cp-In & Arecanut & Areca catechu L. & India & Tropical & R. Bhat & DQ464046 & DQ469730 \\
\hline $1 \mathrm{E}$ & Cacao & Theobroma cacao L. & Brazil & Tropical & E. D. Luz & DQ464047 & -- \\
\hline $4 \mathrm{E}$ & Cacao & Theobroma cacao L. & Brazil & Tropical & E. D. Luz & DQ464048 & -- \\
\hline $23 \mathrm{E}$ & Cacao & Theobroma cacao L. & Brazil & Tropical & E. D. Luz & DQ464049 & -- \\
\hline $59 \mathrm{Ea}$ & Cacao & Theobroma cacao L. & Brazil & Tropical & E. D. Luz & DQ464050 & DQ469731 \\
\hline $106 \mathrm{E}$ & Cacao & Theobroma cacao L. & Brazil & Tropical & E. D. Luz & -- & \\
\hline $182 \mathrm{E}$ & Rubber & $\begin{array}{l}\text { Hevea brasiliensis (Willd. ex Adr. } \\
\text { Juss.) Müll. Arg. }\end{array}$ & Brazil & Tropical & E. D. Luz & DQ464051 & -- \\
\hline $183 \mathrm{E}$ & Rubber & $\begin{array}{l}\text { Hevea brasiliensis (Willd. ex Adr. } \\
\text { Juss.) Müll. Arg. }\end{array}$ & Brazil & Tropical & E. D. Luz & DQ464052 & -- \\
\hline $185 \mathrm{E}$ & Rubber & $\begin{array}{l}\text { Hevea brasiliensis (Willd. ex Adr. } \\
\text { Juss.) Müll. Arg. }\end{array}$ & Brazil & Tropical & E. D. Luz & DQ464053 & -- \\
\hline $197 \mathrm{E}$ & Rubber & $\begin{array}{l}\text { Hevea brasiliensis (Willd. ex Adr. } \\
\text { Juss.) Müll. Arg. }\end{array}$ & Brazil & Tropical & E. D. Luz & DQ464054 & DQ469732 \\
\hline $215 \mathrm{E}$ & Cacao & Theobroma cacao L. & Brazil & Tropical & E. D. Luz & DQ464055 & DQ469733 \\
\hline CBS 128.23 & Chile pepper & Capsicum annиum L. & New Mexico & Temperate & CBS & DQ464056 & DQ469734 \\
\hline CBS 434.91 & Macadamia & $\begin{array}{l}\text { Macadamia integrifolia Maiden \& } \\
\text { Betche }\end{array}$ & Hawaii & Tropical & CBS & DQ464057 & DQ469735 \\
\hline
\end{tabular}

a Phytophthora capsici (CBS 128.23, IMI 040502) (29) and P. tropicalis (CBS 434.91) (4) are the type isolates for their respective species.

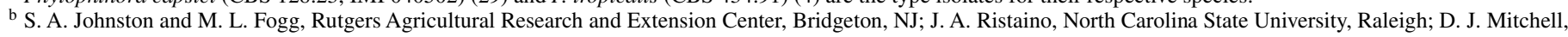
University of Florida, Gainesville; C. Davidson, University of Delaware, Newark; R. Bhat, University of California-Davis, Salinas; E. D. Luz, CEPLAC, Itabuna, Brazil; and CBS, Centraalbureau voor Schimmelcultures, Utrecht, the Netherlands.

c ITS = internal transcribed spacer.

d Not done. 
Park) with an Applied Biosystems DNA sequencer model 3730 using the amplification primers and BigDye Terminator Sequencing kit (Applied Biosystems, Foster City, CA). Sequences were edited using Biological Sequence Alignment Editor (BioEdit ver. 5.0.9, Tom Hall, Ibis Therapeutics, Carlsbad, CA).

Amplification of the $\operatorname{cox}$ I and II gene cluster and sequenceing of the cox II gene. A region spanning the cox I and cox II genes was amplified by PCR using primers FM75 (5'CCTTGGCAATTAGGATTTCAAGAT-3') and FM83 (5'-CTCCAATAAAAAATAACCAAAAATG-3') as previously described (33). Sequencing templates were purified by using a QIAquick PCR Purification kit following the manufacturer's instructions. After the last centrifugation the supernatant was adjusted to $2.0 \mathrm{M}$ $\mathrm{NH}_{4} \mathrm{OAc}$, and then the DNA was precipitated with $100 \%$ ethanol at $-2{ }^{\circ} \mathrm{C}$. Following centrifugation, the DNA pellet was rinsed with $70 \%$ ethanol and dried prior to resuspension in sterile TE. All sequencing was done by the DNA Sequencing Laboratory of the Interdisciplinary Center for Biotechnological Research of the University of Florida (Gainesville, FL) using a ABI 373a automated sequencer (Applied Biosystems). Templates were sequenced in both directions with primer FM75 as well as additional internal primers FM78 (5'-ACAAATTTCACTACATTGTCC-3'), FM79 (5'-GGACAATGTAGTGAAATTTGT-3') and FM80 (5'-AATATCTTTATGATTTGTTGAAA-3'). Primers were synthesized by Invitrogen Corp.

Phylogenetic analysis. A consensus sequence was obtained after alignment of sequences of both strands using the computer program Sequencher ver. 4.1 (Gene Codes, Ann Arbor, MI). A total of $752 \mathrm{bp}$ were used for the ITS analysis and $667 \mathrm{bp}$ were used for the $\operatorname{cox}$ I and II gene cluster. Sequence alignments for the ITS and cox II gene were optimized using MacClade version 4.02 (Sinaur Assoc., Sunderland, MA), and PAUP version 4.0b10 (Sinaur Assoc.) was used for phylogenetic analyses. Phylogenetic relationships among Phytophthora spp. using DNA sequence data were inferred by maximum parsimony (MP) analysis with a heuristic tree search. Heuristic searches were performed with MULPARS on, steepest decent option off, random addition of sequences (100 replicates) and TBR branch swapping. To determine support for the various clades of the trees, the analysis described above was bootstrapped with 1,000 replicates with the same conditions noted above, with the exception that there were 10 replicates for the random addition of samples. Data for an isolate of Pythium aphanidermatum from Mexico (1987-61), Pythium ultimum from Florida (110-2), and Phytophthora spp. previously reported $(32,33)$ also were included in the analysis. Phylogenetic inferences based on ITS and 5.8S rDNA sequence data were based on the results of Cooke et al. (9) with the alignments retrieved from TreeBASE (accession M751) and modified as in Martin and Tooley (33) (TreeBASE accession SN 774). DNA sequence data obtained in this study have been deposited in GenBank (Table 1) and the results of the phylogenetic analysis have been deposited in TreeBASE (S1662).

RFLP analysis of $\operatorname{cox}$ I and II gene cluster and ITS regions. RFLP analysis of the cox I and II gene cluster generated by amplification using FM75 and FM83 was conducted as previously described (34). All amplifications were separated on a $1.5 \%$ agarose gel to check DNA concentration and purity prior to digestion. The restriction enzymes $A l u \mathrm{I}, M s p \mathrm{I}, R s a \mathrm{I}$, and $T a q \mathrm{I}$ were used in accordance with the manufacturer's instructions (New England BioLabs) and the fragments were separated on a 3\% NuSieve 3:1 gel (Cambrex Bio Science, Rockland, ME) in $0.5 \times$ TBE buffer (0.045 M Tris-borate, 0.001 M EDTA, $\mathrm{pH} 8.0$ ) at $45 \mathrm{~V}$ for $6 \mathrm{~h}$ or until the bromophenol blue dye in the loading buffer had migrated $8 \mathrm{~cm}$ from the well. A 100-bp ladder (New England BioLabs) mixed with a nondigested amplicon from $P$. infestans (isolate 580; approximately $2.2 \mathrm{~kb}$ based on sequence analysis) provided size markers. The gel was stained in ethidium bromide $(0.5 \mu \mathrm{g} / \mathrm{ml})$ for $30 \mathrm{~min}$, destained in deionized water for $30 \mathrm{~min}$, and photo- graphed under short wave UV using either Polaroid Type 55 film or an ERDAS imaging system (Kodak, Rochester, NY). RFLP analysis of the ITS region that was amplified with ITS6 and ITS4 was done as reported by Cooke et al. (11). The amplicons were digested with $A l u \mathrm{I}, M s p \mathrm{I}$, or TaqI and separated by agarose gel electrophoresis using the same procedures noted above for the cox gene cluster.

Scanned digital images of the Polaroid negatives were imported into the computer program BioNumerics (ver. 2.5, Applied Maths, Sint-Martens-Latem, Belgium). This computer program automatically determines the molecular size of the RFLP bands relative to molecular size standards included on each agarose gel. The images were processed using standard procedures and molecular size determinations of digested bands were done automatically with manual confirmation. To optimize band matching between isolates, the positional tolerance of each band (the maximum shift between two bands that is allowed to consider the bands matching, expressed as a percentage of the length of the gel run) and optimization of the data (this allows for a shift between any two patterns to optimize comparisons of banding patterns, expressed as a percentage of the run length) were determined from the data using the tolerance and optimization options of the program. Positional tolerances of $1.06,1.0,1.16$, and $1.0 \%$ were obtained for AluI, MspI, RsaI, and TaqI, respectively. Optimization was determined to be 0 except for $R s a \mathrm{I}$, which was set at $0.54 \%$. Bands less than $100 \mathrm{bp}$ in size were excluded from the analysis due to the diffuse nature of the bands when using a 3\% NuSieve 3:1 agarose gel. In addition to band size determinations, BioNumerics performed cluster analysis to evaluate the similarity in restriction banding profiles among the various species evaluated. For comparison with other species in the genus, data from a prior analysis of the genus were included in this analysis (34).

\section{RESULTS}

Radial growth rates and chlamydospore formation. Radial growth of the isolates and chlamydospore formation are presented in Table 2. All isolates grew at $28^{\circ} \mathrm{C}$. With one exception (isolate $\mathrm{B} 2 \mathrm{HH} 4$ ), all isolates originating from a temperate climate grew at $35^{\circ} \mathrm{C}$, while those from the tropical climate did not. All but two isolates from the tropical group of isolates formed chlamydospores via the submerged culture method. Conversely, no chlamydospores were observed in isolates within the temperate group.

AFLP analysis. Data from the four primer combinations, EcoRI-AG, -AC, -AA, and -AT, each in combination with MseI-C, resulted in a total of 540 polymorphic loci, with $140,162,115$, and 123 polymorphic loci, respectively. Similarities among isolates of P. capsici based on AFLP analysis using Jaccard's similarity coefficient and the UPGMA tree building algorithm were supported by bootstrap analysis (Fig. 1). The dendrogram clearly separated the temperate isolates of $P$. capsici from the tropical isolates and from isolates classified as $P$. tropicalis with high bootstrap values (above 90\%). Within the temperate group, the majority of the isolates clustered within a single clade (Fig. 1, clade A), however, there was good bootstrap support for the separate grouping of three temperate isolates (isolates 23, 223, and 230). Within the temperate clade A there was not any specific grouping of isolates for host or geographic recovery, although the grouping of two isolates each from bell pepper recovered from Florida and New Jersey was supported by bootstrap analysis.

The tropical isolates grouped into three distinct clades (Fig. 1). Clade B was comprised entirely of isolates recovered from cacao or rubber in Brazil, while clade $\mathrm{C}$ contained a mixture of isolates, including the type culture of $P$. tropicalis from macadamia in Hawaii, an isolate from black pepper in Puerto Rico, and an isolate from arecanut in India. Clade D constituted a separate grouping and contained isolates from cacao in Brazil. 
TABLE 2. Radial growth of temperate and tropical isolates of Phytophthora capsici at 28 and $35^{\circ} \mathrm{C}$ in darkness, and resulting chlamydospore formation

\begin{tabular}{lccc}
\hline & \multicolumn{2}{c}{ Colony diameter at $48 \mathrm{~h}(\mathrm{~mm})$} & Chlamydospore \\
Isolate & $28^{\circ} \mathrm{C}$ & $35^{\circ} \mathrm{C}$ & formation \\
\hline Temperate group & & & - \\
Pc-W3a & 42.0 & 9.5 & - \\
R699 & 25.6 & 16.1 & - \\
R1198 & 39.6 & 9.4 & - \\
R1298 & 38.6 & 5.4 & - \\
Cp-D2 & 31.8 & 23.5 & - \\
Cp-D3 & 26.5 & 22.9 & - \\
B2H4 & 23.2 & 0.1 & - \\
RA1 & 40.4 & 7.9 & - \\
RA4 & 35.5 & 15.9 & + \\
220 & 42.0 & 13.1 & + \\
Tropical group & & & + \\
23E & 39.6 & 0 & + \\
23-1E & 38.7 & 0 & + \\
59Ea & 36.1 & 0 & - \\
183E & 18.5 & 0 & - \\
197E & 27.1 & 0 & + \\
215E & 34.9 & 0 & + \\
Cp-1 & 39.5 & 0 & \\
Cp-2 & 28.4 & 0 & + \\
Cp-In & 31.2 & 0 & - \\
CBS 434.91 (type) & 42.0 & 0 & - \\
MSD value & 1.78 & 1.57 & \\
\hline
\end{tabular}

${ }^{\text {a }}$ Colony diameter was measured in millimeters $(\mathrm{mm})$ at the narrowest and widest points and then the two numbers were averaged after subtracting the $6 \mathrm{~mm}$ diameter of the agar transfer plug.

${ }^{\mathrm{b}}$ Waller-Duncan k-ratio $t$ test; $\mathrm{MSD}=$ minimum significant difference, $\mathrm{k}=100$.

${ }^{\mathrm{c}}$ Chlamydospore formation after 8 weeks at $16^{\circ} \mathrm{C}$ following submerged culture method of Uchida and Aragaki (46); + and - indicate formation and no formation of chlamydospores, respectively.
Phylogenetic analysis. Isolate groupings for the ITS data were the same as those observed with the AFLP data, with the temperate isolates forming a single clade and the tropical isolates clustering into three clades, some of which also were supported in bootstrap analysis (Figs. 2 and 3). One noticeable difference was for temperate isolates 23,230, and 223, which were distantly grouped with the other temperate isolates in the AFLP analysis, but were within the same clade in the ITS analysis (Figs. 2 and 3). Comparisons with sequences of other isolates downloaded from GenBank revealed a clear separation of tropical and temperate isolates and a lack of grouping of isolates from a particular host or geographical location (Fig. 2). The only exception to this was clade $\mathrm{D}$, which had isolates from Theobroma cacao recovered from Brazil, Africa, and New Guinea. Sequence divergence between temperate clade A and tropical clade D ranged from approximately 1.0 to $1.6 \%$, but this was greater than sequence divergence within clades. All temperate isolates studied, and those retrieved from GenBank, were grouped in clade A, with a sequence divergence within the clade of only $0.4 \%$. Isolates from different hosts and geographical area were grouped together. In contrast, sequence variation among the three tropical clades was greater, with a 0.7 to $0.8 \%$ sequence divergence between tropical clades $\mathrm{B}$ and $\mathrm{C}$ as well as between clades $\mathrm{B}$ and $\mathrm{D}$, and 1.0 to $1.3 \%$ sequence divergence between clades D and C. However, sequence divergence between temperate and tropical isolates within the ITS regions was more than in comparisons among other closely related species such as $P$. infestans, $P$. mirabilis, and $P$. phaseoli (from 0.1 to $0.6 \%$ ) or $P$. cactorum and P. pseudotsugae ( $0.6 \%)$.

The same groupings were observed for the analysis of the cox I and II gene region although there was no bootstrap support for this separation. The temperate isolates grouped together while the
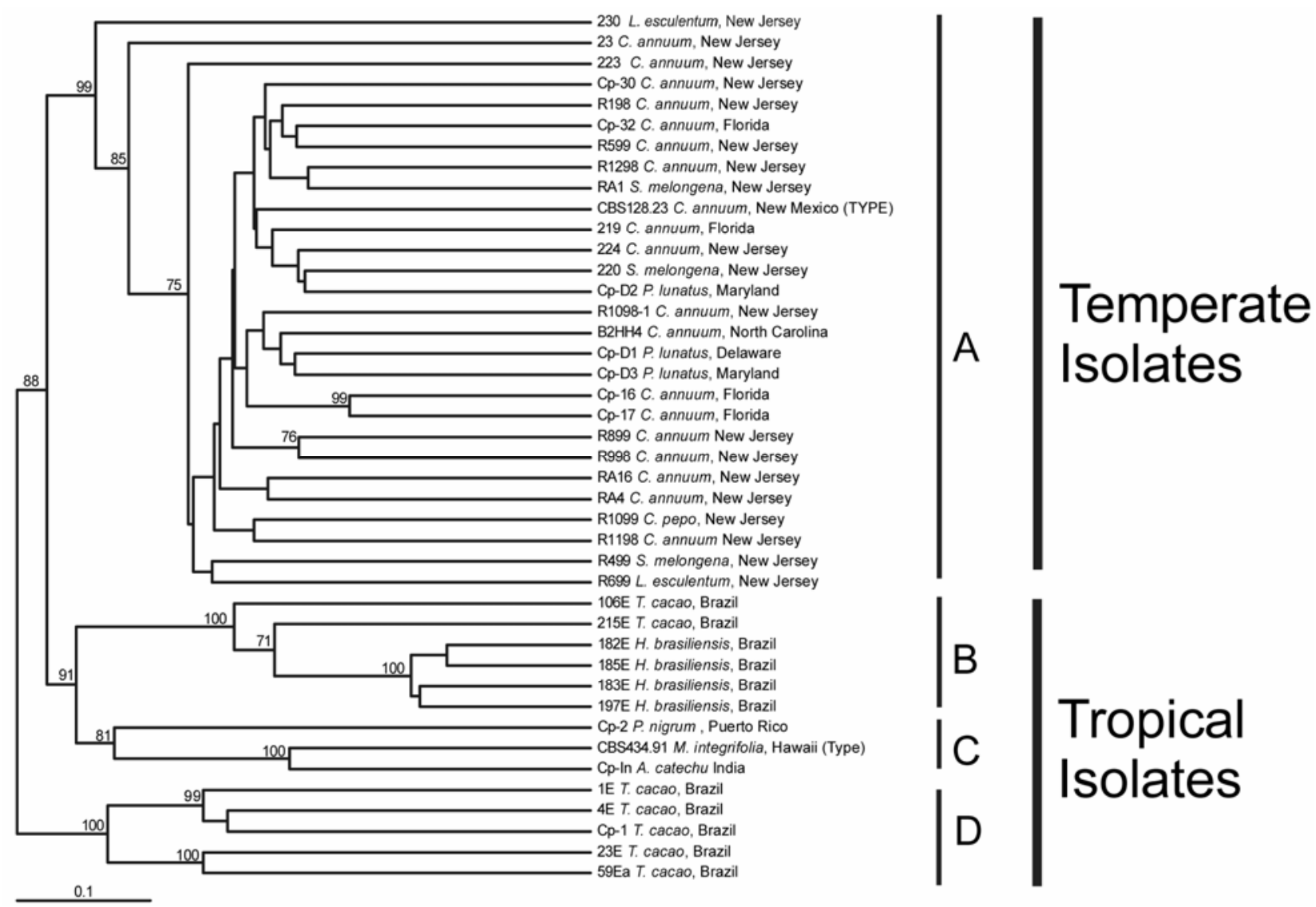

Fig. 1. Unweighted pair-group method, arithmetic mean cluster analysis showing similarities among isolates of Phytophthora capsici based on amplified fragment length polymorphism analysis using Jaccard's similarity coefficient. The numbers at the nodes are the percentage of the trees above $70 \%$ that were supported by bootstrap analysis (1,000 replications). Data from four primer combinations were combined for the analysis with a total of 540 polymorphic markers (EcoRI-AG, -AC, -AA, and -AT, each in combination with MseI-C with 140, 162, 115, and 123 polymorphic markers, respectively). 
tropical isolates were found in three clades, some of which had bootstrap support (Fig. 4). One noticeable difference was observed in clade A, with the $P$. capsici type culture (CBS128.23) and three other isolates grouping together within the clade; this was not observed in the AFLP or ITS analysis. Sequence divergence between temperate and tropical isolates within the cox I and II regions studied ranged from 0.15 to $1.0 \%$. The temperate isolates were very similar, with a sequence divergence of only $0.3 \%$ or less, and among the tropical isolates, the sequence divergence ranged from 0.15 to $0.75 \%$. The sequence divergence between temperate (clade A) and tropical (clade C) isolates was similar $(0.1$ to $0.6 \%)$ to the level of variation observed among the tropical isolates. As a comparison, the sequence divergence observed among the $P$. infestans, $P$. mirabilis, and $P$. phaseoli group was 0.6

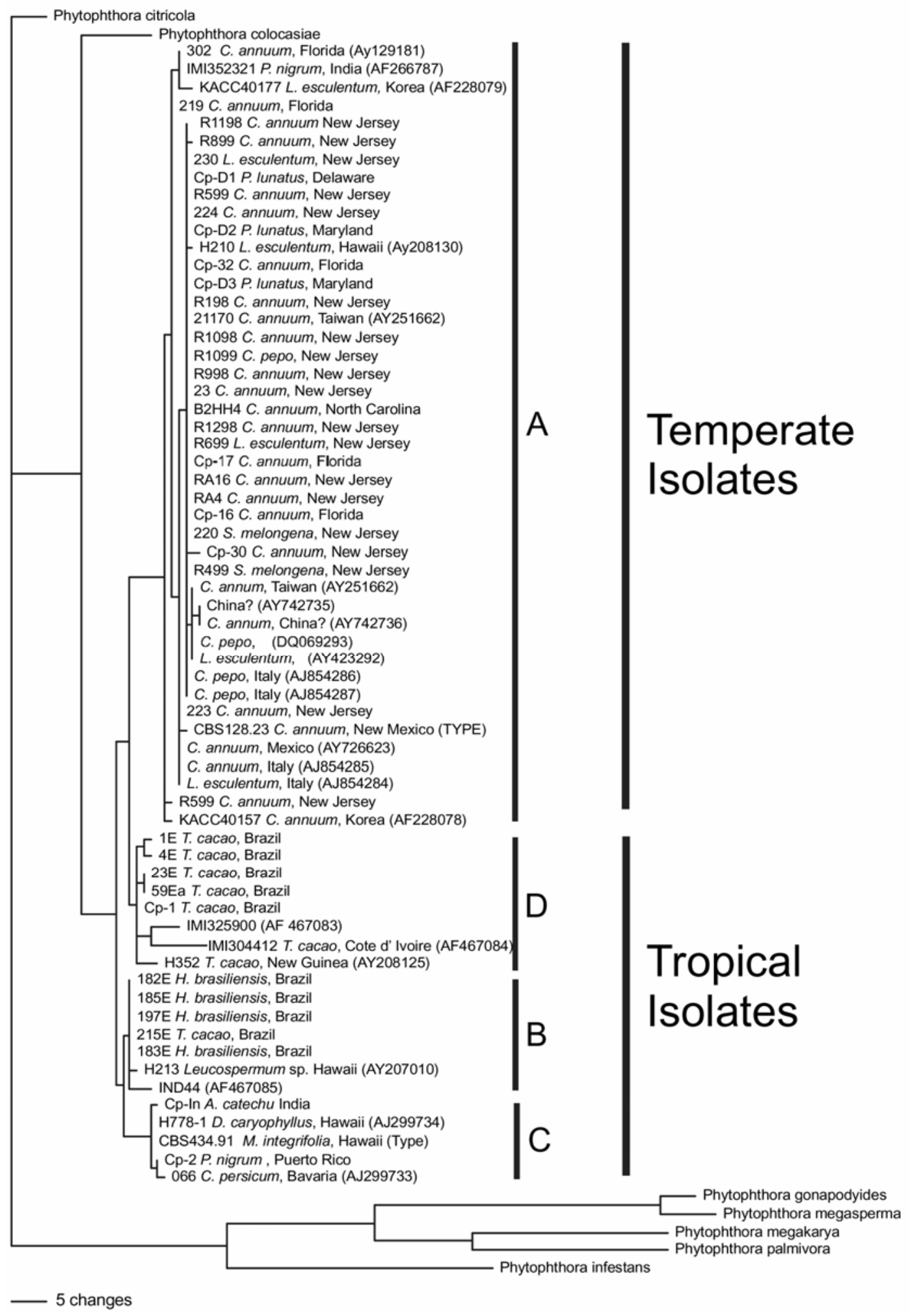

Fig. 2. One of 120 most parsimonious trees for Phytophthora spp. obtained using internal transcribed spacer DNA sequence data based on maximum parsimony inferred by a heuristic tree search. Of the 835 total characters, 624 were constant, 107 were variable and parsimony uninformative, and 104 were parsimony informative. Tree length $=288$, consistency index $=0.833$, homoplasy index $=0.167$, and retention index $=0.894$. Data for species other than $P$. capsici and $P$. tropicalis were from alignments in Martin and Tooley (33). Letters to the right of the clades correspond to the clade lettering in Figure 1. 
to $0.9 \%$, and there was good bootstrap support to separate these species into distinct groups.

RFLP analysis of PCR amplified products. Cluster analysis of the cox I and II gene cluster RFLP data exhibited similarity to the groupings observed in the AFLP, ITS and cox II sequence data with some notable exceptions (Fig. 5). While clade D isolates grouped alone on the same clade, isolates from clade B and C had the same RFLP pattern and were together on the same clade in this analysis. Surprisingly, the type culture for P. capsici (a temperate, clade A isolate in prior analysis) was also on this same clade. Isolates from clade A were found on three separate groupings with no apparent association with host or geographic location of recovery. All tropical and temperate isolates grouped together and were separate from other species. RFLP fragment sizes were similar to

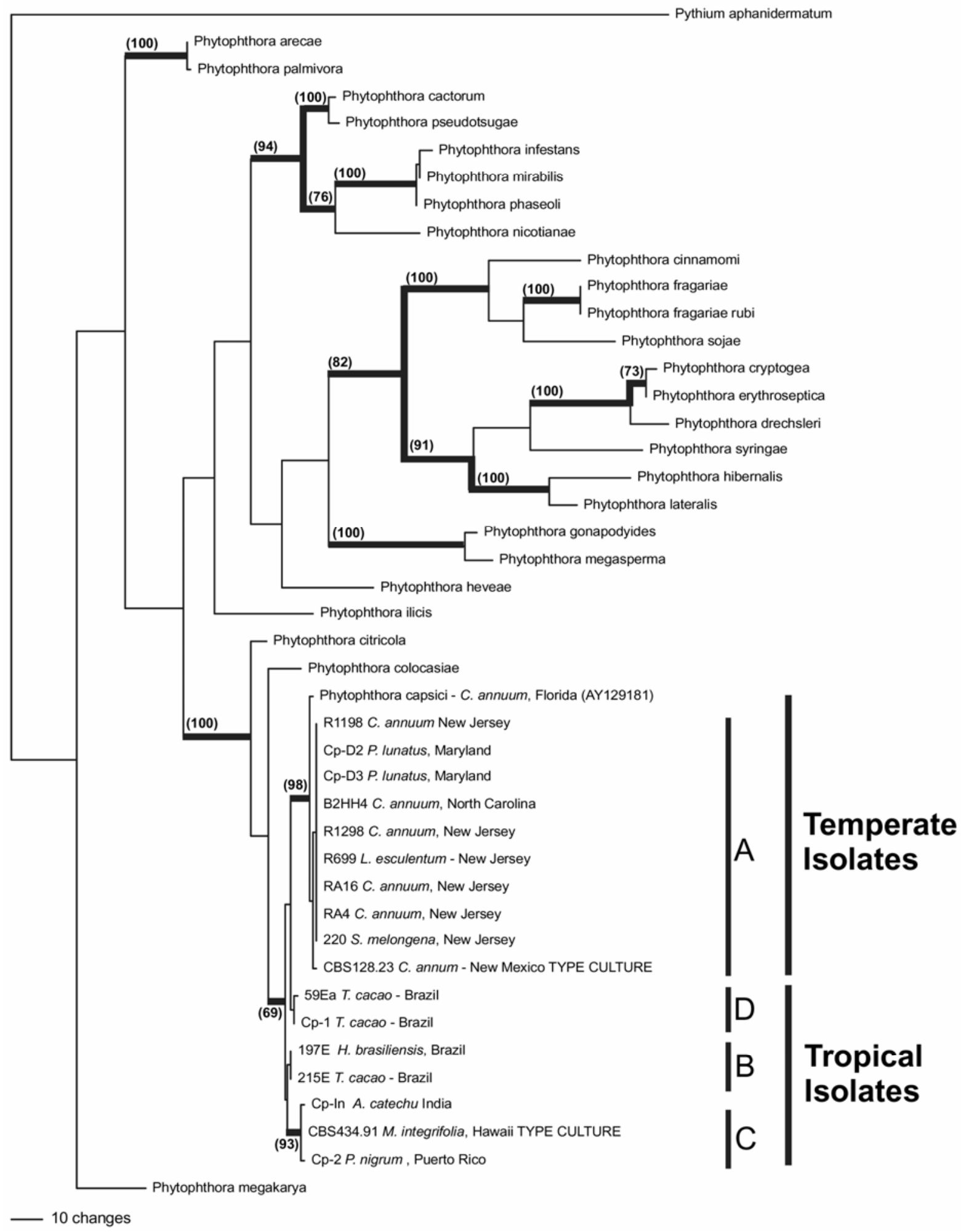

Fig. 3. The most parsimonious tree for Phytophthora spp. obtained using internal transcribed spacer DNA sequence data based on maximum parsimony inferred by a heuristic tree search. Thick branch lines represent clades that were supported by bootstrap analysis (1,000 replications), with the numbers in brackets at the nodes the percentage of the trees above $70 \%$ that support the observed topography. Letters to the right of the clades correspond to the clade lettering in Fig. 1. Of the 906 total characters, 467 were constant, 194 were variable and parsimony uninformative, and 245 were parsimony informative. Tree length $=982$, consistency index $=0.632$, homoplasy index $=0.368$, and retention index $=0.759$. 
those previously reported for three of the isolate groupings (represented by isolates 302, Cp-30, and 59Ea) (34), but three unique RFLP groupings were observed that differed by the loss of a TaqI site (isolates CBS 128.23 and CBS 434.91) or differences in MspI restriction sites (isolates CBS 128.23, CBS 434.91 and 220; Table 3).
For the ITS RFLP analysis, the temperate isolates (clade A1, A2, and A3) all grouped in the same major clade separately from the tropical isolates. The groupings of the tropical isolates were reflective of what was observed in the other analysis, with clade $\mathrm{B}$ and $\mathrm{C}$ more closely affiliated with each other than with clade D (Figs. 1-4). Fragment sizes were similar to what was previously

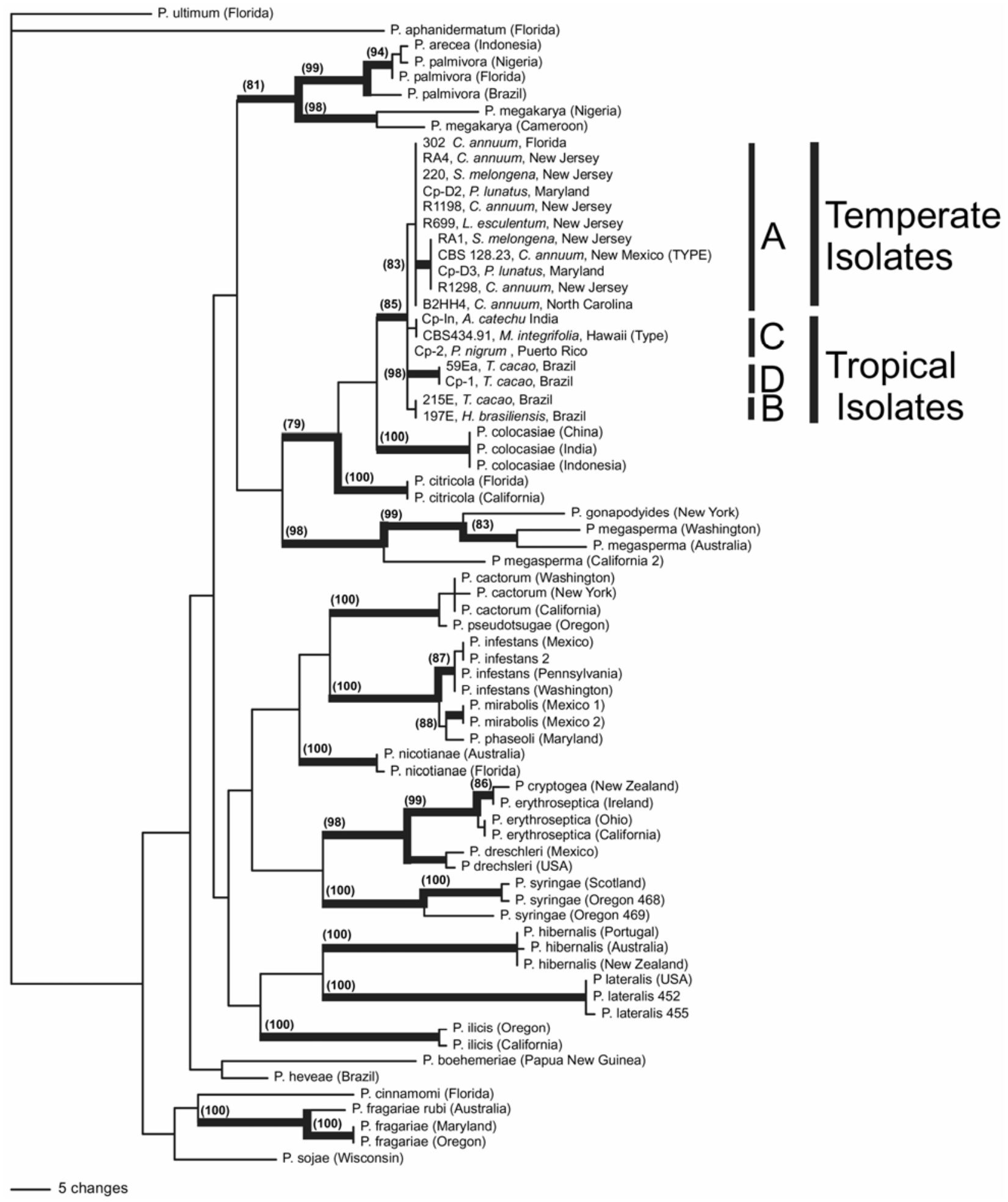

Fig. 4. One of 19 most parsimonious trees for Phytophthora spp. using cox II DNA sequence data based on maximum parsimony inferred by a heuristic tree search. Thick branch lines represent clades that are supported by bootstrap analysis (1,000 replications), with the numbers in brackets at the nodes the percentage of the trees above $70 \%$ that support the observed topography. Letters to the right of the clades correspond to the clade lettering in Figure 1.0 f the 667 total characters, 466 were constant, 37 were variable and parsimony uninformative, and 164 were parsimony informative. Tree length $=617$, consistency index $=0.462$, homoplasy index $=0.538$, and retention index $=0.794$. Isolates marked with an asterisk are the same cultures that were used in this submission to infer the internal transcribed spacer-based phylogenetic tree in Fig. 2. Data for species other than P. capsici and P. tropicalis were from alignments in Martin and Tooley (34). 


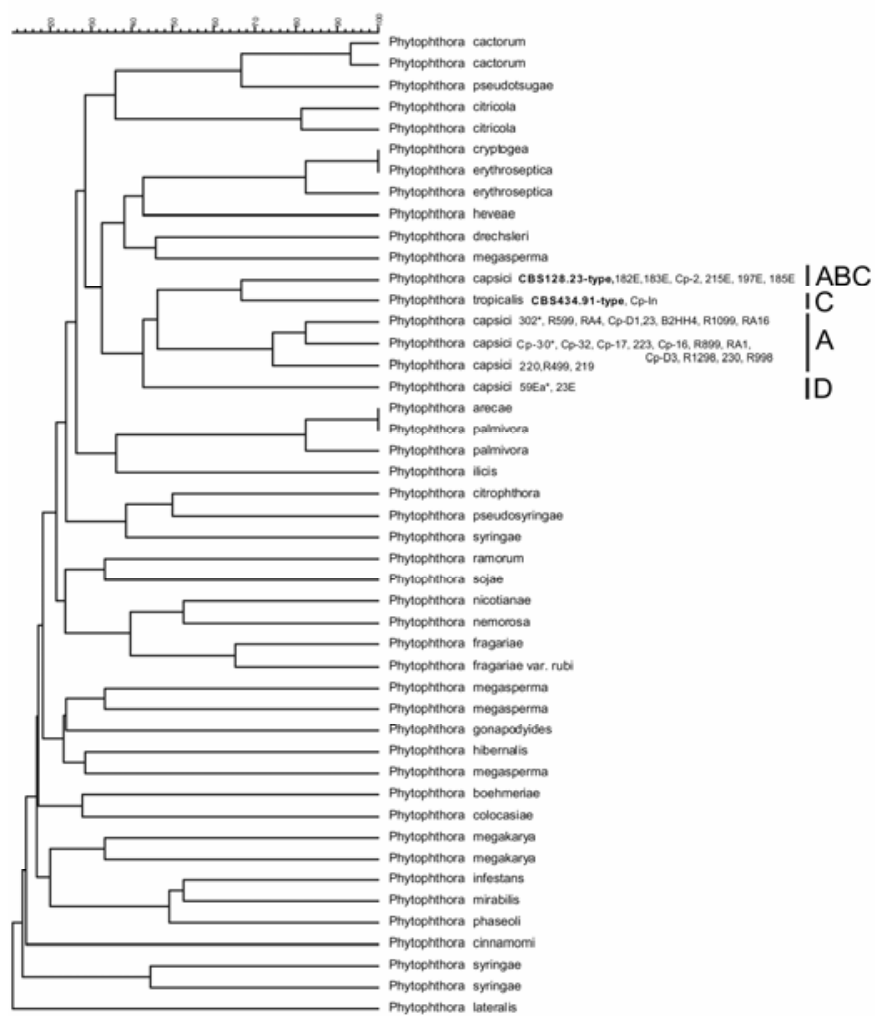

Fig. 5. Unweighted pair-group method arithmetic mean cluster analysis using Jaccard's similarity coefficients of the $A l u \mathrm{I}, M s p \mathrm{I}, R s a \mathrm{I}$, and $T a q \mathrm{I}$ restriction fragment linked polymorphism restriction profiles of the polymerase chain reaction-amplified product spanning the cox I and II gene cluster generated using primers FM 75 and FM 77/83. The scale at the top represents percent similarity. Data for species other than P. capsici and P. tropicalis can be found in Martin and Tooley (34). Letters to the right of the clades correspond to the clade lettering in Figure 1. reported by Cooke et al. (11) with a few exceptions (Table 4). Isolates in clade $\mathrm{C}$ (represented by the type culture of $P$. tropicalis CBS 434.91) had an additional band at approximately 694 bp following $A l u \mathrm{I}$ digestion, while isolates on clade $\mathrm{D}$ (represented by isolate $23 \mathrm{E}$ ) had a unique $A l u \mathrm{I}$ restriction profile.

\section{DISCUSSION}

The taxonomic classification of $P$. capsici isolates recovered from hosts in tropical and temperate climates has been an evolving concept $(2,4,36,37,43,49)$. In this current study, an additional 28 temperate and 14 tropical isolates of $P$. capsici/P. tropicalis (including the type cultures) were examined using morphological and molecular criteria to evaluate isolates of the species. We asked if the observed differences were enough to warrant the designation of a new species as has been suggested (4), or if these differences represent a level of variability reflective of the species.

Two features reported to correspond with the separation of these species are growth at $35^{\circ} \mathrm{C}(P$. capsici) and formation of chlamydospores (P. tropicalis) (4). Based strictly on these criteria the temperate and tropical isolates examined in this study were separated. All isolates tested were able to grow on agar medium at $28^{\circ} \mathrm{C}$, but only the temperate isolates grew at $35^{\circ} \mathrm{C}$ (Table 2). None of the temperate isolates were able to form chlamydospores using the submerged culture method, but 8 of 10 tropical isolates did. This lack of chlamydospore formation in some tropical isolates has been reported previously $(1,43,45)$.

In the AFLP analysis there also was a distinction between temperate and tropical isolates, and this separation was supported by bootstrap analysis (Fig. 1). Most of the temperate isolates grouped together in the same clade, while the tropical isolates appeared to represent an assemblage of distinct genetic lineages. Groupings of isolates within clades appeared to be independent of host and geographical origin. Bootstrap analysis supported placing 25 of 28 of the temperate isolates in one clade, with the remaining three isolates closely related. The tropical isolates, on the other hand, were

TABLE 3. Size, in number of base pairs (bp), of restriction fragments for the cox I and II gene cluster amplified with primers FM75 and FM77/83 from Phytophthora spp. and digested with the indicated restriction enzyme

\begin{tabular}{|c|c|c|c|c|c|}
\hline Phytophthora sp. & Isolate \# & $A l u \mathrm{I}$ & $M s p \mathrm{I}$ & $R s a \mathrm{I}$ & TaqI \\
\hline P. capsici & $\begin{array}{l}302^{\mathrm{b}} \\
\mathrm{Cp}-30^{\mathrm{b}} \\
59 \mathrm{Ea}^{\mathrm{b}} \\
\text { CBS } 128.23\end{array}$ & $\begin{array}{l}697 ; 451 ; 227 ; 203 ; 179 ; 132 \\
697 ; 451 ; 227 ; 203 ; 179 ; 132 \\
720 ; 451 ; 227 ; 203 ; 179 ; 132 \\
697 ; 451 ; 227 ; 203 ; 179 ; 132\end{array}$ & $\begin{array}{l}\text { Uncut } \\
1,415 ; 901 \\
1,140 ; 1,080 \\
\text { Uncut }\end{array}$ & $\begin{array}{l}712 ; 550 ; 332 ; 300 ; 226 ; 182 \\
712 ; 550 ; 332 ; 300 ; 226 ; 182 \\
712 ; 550 ; 332 ; 300 ; 226 ; 182 \\
712 ; 550 ; 332 ; 300 ; 226 ; 182\end{array}$ & $\begin{array}{l}1,573 ; 743 \\
1,573 ; 743 \\
1,187 ; 834 \\
\text { Uncut }\end{array}$ \\
\hline P. tropicalis & $\begin{array}{l}\text { CBS } 434.91 \\
220\end{array}$ & $\begin{array}{l}697 ; 451 ; 227 ; 203 ; 179 ; 132 \\
697 ; 451 ; 227 ; 203 ; 179 ; 132\end{array}$ & $\begin{array}{l}1,462 ; 711 \\
1,170(2 x)\end{array}$ & $\begin{array}{l}712 ; 550 ; 332 ; 300 ; 226 ; 182 \\
712 ; 550 ; 332 ; 300 ; 226 ; 182\end{array}$ & $\begin{array}{l}\text { Uncut } \\
1,573 ; 743\end{array}$ \\
\hline
\end{tabular}

a Amplified products were digested with the indicated restriction enzyme and separated in a 3\% NuSieve 3:1 agarose gel. Fragment sizes were determined and the database managed using the computer program BioNumerics (ver. 2.5). While fragment sizes are reported to the base pair by BioNumerics, this level of accuracy is artificial and not supported by the agarose electrophoresis method used for estimation. Doublet bands and fragment sizes smaller than 100 bp are not reported or included in the cluster analysis.

b Same sizes as reported in Martin and Tooley (34).

TABLE 4. Size, in number of base pairs, of restriction fragments for Phytophthora spp. amplified with primers ITS1 and ITS4 and digested with the indicated restriction enzyme

\begin{tabular}{llclll}
\hline Phytophthora sp. & Clade & Isolate \# & \multicolumn{1}{c}{ AluI } & MspI & TaqI \\
\hline P. capsici & A1 & RA1 & $155 ; 172 ; 535^{\mathrm{b}}$ & $145 ; 204 ; 221 ; 292^{\mathrm{b}}$ & $46 ; 59 ; 90 ; 101 ; 148 ; 194 ; 263^{\mathrm{c}}$ \\
& A2 & CBS 128.23 & $155 ; 172 ; 535^{\mathrm{b}}$ & $145 ; 204 ; 221 ; 292 ; 349^{\mathrm{c}}$ & $46 ; 59 ; 90 ; 101 ; 148 ; 194 ; 263^{\mathrm{c}}$ \\
& A3 & Cp-17 & $155 ; 172 ; 535^{\mathrm{b}}$ & $145 ; 204 ; 221 ; 292^{\mathrm{b}}$ & $46 ; 59 ; 90 ; 101 ; 148 ; 263^{\mathrm{b}}$ \\
P. tropicalis & C & CBS 434.91 & $155 ; 172 ; 535 ; 694$ & $221 ; 292 ; 349^{\mathrm{d}}$ & $59 ; 90 ; 100 ; 149 ; 194 ; 263^{\mathrm{d}}$ \\
& B & $185 \mathrm{E}$ & $155 ; 172 ; 535^{\mathrm{b}, \mathrm{c} \text { d }}$ & $221 ; 292 ; 349^{\mathrm{d}}$ & $59 ; 90 ; 100 ; 149 ; 194 ; 263^{\mathrm{d}}$ \\
& D & $23 \mathrm{E}$ & $183 ; 694$ & $221 ; 292 ; 349^{\mathrm{d}}$ & $59 ; 90 ; 100 ; 149 ; 194 ; 263^{\mathrm{d}}$ \\
\hline
\end{tabular}

\footnotetext{
${ }^{a}$ Amplified products were digested with the indicated restriction enzyme and separated in a 3\% agarose gel. While fragment sizes are reported to the base pair, this level of accuracy is artificial and is not supported by the agarose electrophoresis method used for estimation. These sizes are included for purposes of comparison with the results of Cooke et al. (11).

${ }^{\mathrm{b}}$ Results are the same as reported by Cooke et al. (11) for P. capsici.

${ }^{\mathrm{c}}$ Results are the same as reported by Cooke et al. (11) for P. capsici combination.

${ }^{\mathrm{d}}$ Results are the same as reported by Cooke et al. (11) for $P$. capsici variant.
} 
separated into three clades, all strongly supported by bootstrap analysis. Clades B and C (which included the type culture for $P$. tropicalis) grouped together and were affiliated more closely with the temperate isolates in clade A than with other tropical isolates in clade D (comprised of Brazilian isolates from $T$. cacao), which were more distantly related. A similar grouping of isolates recovered from $T$. cacao in Brazil also was reported in isozyme analyses $(36,37)$.

Analysis of ITS DNA sequence data of the species revealed similar groupings and variation within and among clades as did the AFLP analysis (Fig. 2). However, sequence divergence among isolates and clades was relatively low. More sequence variation was present within the three clades of tropical isolates than within the temperate clade. Clade D isolates, recovered from $T$. cacao from different regions of the world, grouped separately from other tropical isolates in both analyses and may be indicative of a subpopulation. Silvar et al. (41), using random amplified polymorphic DNA analysis, found little variation among Spanish isolates of $P$. capsici, and more variation among predominately tropical isolates. This is similar to our findings of low variation among temperate, North American isolates, and greater variation among tropical isolates. In our study when the phylogenetic analyses were rerun to include more species of the genus, similar groupings were observed, with the branch lengths separating temperate and tropical isolates shorter than the branch lengths separating most other species (Fig. 3). The temperate and tropical isolates were related more to each other than to closely related $P$. colocasiae. In this analysis, however, there were groups of recognized species ( $P$. infestans, $P$. mirabilis, and $P$. phaseoli or $P$. cryptogea and $P$. erythroseptica) that exhibited less sequence divergence than observed between the temperate and tropical groups. This data set, then, presents evidence that could be used to both support and not support the separation of temperate and tropical isolates of $P$. capsici. Thus, decisions on speciation based on results of ITS sequence analysis alone may not be appropriate in this situation. The inclusion of the cox II DNA sequence data did not resolve the issue further, as the separation of the temperate and tropical isolates was even less clear (Fig. 4). While there was bootstrap support for separating these isolates from other species, there was no support for separating the temperate and tropical isolates.

In a similar analysis with another species of Phytophthora, Ivors et al. (21) found clear differences between isolates of $P$. ramorum from the United States and Europe using AFLP analysis, but phylogenetic analyses revealed no differences in the DNA sequences of three different genes (ITS, cox II, and nad 5). Even though isolates from different populations within the species can be differentiated using AFLP analysis, all are considered to be of the same species. Like $P$. ramorum, $P$. capsici may consist of different populations within the species.

While not intended to be used to support phylogenetic relationships between temperate and tropical isolates, RFLP analysis of the mitochondrially encoded cox I and II gene cluster and nuclear encoded ITS can be used to help identify isolates into specific subgroups. Restriction profile analysis of the cox gene cluster separated the $P$. capsici isolates from other species, but did not distinguish between temperate and tropical isolates (Fig. 5). A group of temperate isolates was clustered with tropical isolates, and the type isolate of $P$. capsici, a temperate isolate, was clus-

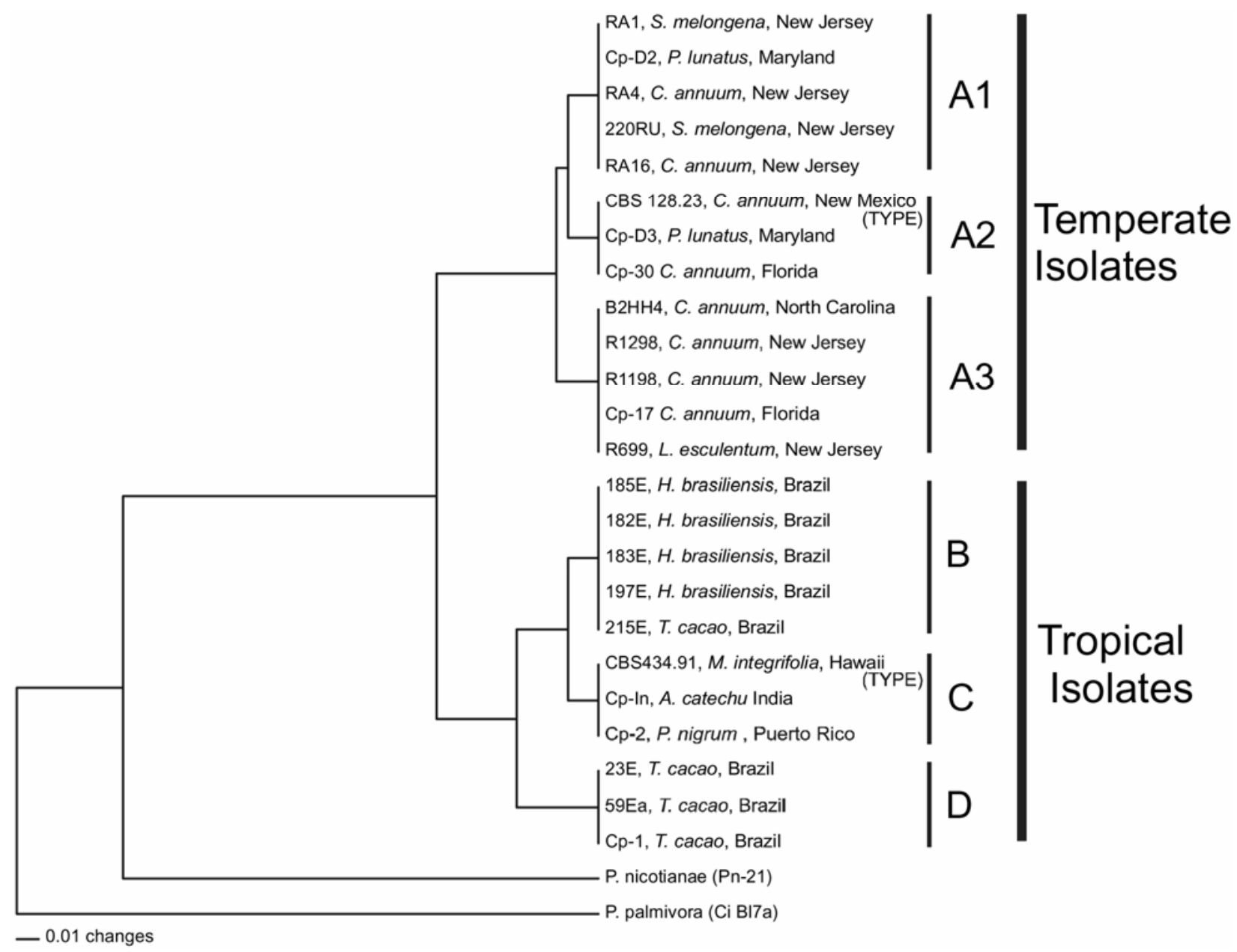

Fig. 6. Unweighted pair-group method arithmetic mean cluster analysis of Phytophthora spp. using Jaccard's similarity coefficients of the AluI, MspI, and TaqI restriction fragment linked polymorphism restriction profiles of the internal transcribed spacer region of rDNA region amplified using primers ITS1 and ITS4. Letters to the right of the clades correspond to the clade lettering in Figure 1. 
tered with tropical isolates (clade $\mathrm{ABC}$ ). Analysis of restriction profiles of the ITS region of the rDNA separated the temperate and tropical isolates in groupings similar to AFLP and ITS phylogenetic analysis (Fig. 6). The same three clades were observed within the tropical group, but the temperate group of isolates was grouped into three subclades with no association with regard to host or geographic origin. Based on the band sizes observed, these restriction profiles may allow for groups within species identification when compared to data from the genus as a whole (11). This statement also may be true of the SSCP analysis (24). An interesting observation from the ITS RFLP data is that the summation of the band sizes was greater than the amplicon size, which indicates heterozygosity for rDNA. This is not surprising given that $P$. capsici is heterothallic and agrees with the findings of Lamour and Hausbeck (27) in Michigan for P. capsici, and with data reported by Martin (31) for Pythium sylvaticum outcrosses. In view of the differences in grouping of isolates in the $\operatorname{cox}$ I and II gene cluster compared with the ITS RFLP analysis, combining these techniques should provide an additional tool for identification of isolate subgroups. One possible reason for the lack of correlation between the cox 1 and II gene cluster and ITS RFLP analysis is that mitochondria are unparentially inherited from the maternal parent in sexual crosses in the genus Phytophthora (14). Given that $P$. capsici is heterothallic and that outcrossing has occurred in the isolates examined in this study (as evidenced by the heterozygosity of the ITS), new combinations of the ITS region could be encountered in progeny with a single cox I and II RFLP pattern.

Many species of Phytophthora have multiple hosts, and P. capsici is no exception (13). However, variation in pathogenicity has been reported within the species depending on the host from which a particular isolate was recovered (39). Uchida and Aragaki (46) reported that isolates of $P$. capsici from macadamia were not pathogenic on pepper, and that all tropical isolates of $P$. capsici tested later were uniformly avirulent on pepper (4). In preliminary tests with the isolates used in this report, both temperate and tropical isolates exhibited a range in virulence when inoculated onto cacao pods, with either group just as likely to cause severe or little symptom development (30). Temperate isolates also caused a range in symptoms when inoculated onto pepper fruits, but tropical isolates caused little or no symptoms. These preliminary results coincide with those of Aragaki and Uchida (4), but based on the variation present in this species and others (22), pathogenicity on a particular host may not be a good indication of species status (13). These results do raise an interesting question. Clearly the temperate isolates still carry the genetic ability to infect cacao, and presumably other tropical crops (although this has yet to be tested). The tropical isolates, on the other hand, appear to have limited genetic ability to infect pepper, a crop to which a tropical population may not have been exposed to in recent time.

Our data, taken as a whole, suggest that the temperate isolates may be members of a population resulting from the introduction of members of a parent tropical population into a new environment. When a species is introduced into a new environment, the small, original population is called a founder population (35). These populations typically go through a biological bottleneck where only a fraction of the individuals survive, e.g., those that could infect solanaceous plants, cucurbit plants, or both, in a temperate environment. Thus, these populations are less diverse genetically than the parent population. Our AFLP and ITS sequence data clearly indicate that the temperate population is less diverse genetically than the tropical population, and that the temperate population is encompassed within the variation present in the parent tropical population. These results are characteristic of the founder effect (35), and suggest that the temperate population was introduced, and has become an invasive population in temperate climates. The results of Silvar et al. (41) for Spanish isolates of
$P$. capsici are an indication that the introduction of the tropical population of the species into a temperate climate may have occurred several times. The relationships among North American and European isolates of $P$. capsici would be important to know to test this hypothesis. Similar arguments were made regarding the introduction of $P$. ramorum into North America and Europe from an unknown source (21).

These two populations of $P$. capsici, however, may not yet be sufficiently isolated to justify separate species status. The low level of sequence variation between the two populations in the mitochondrial cox II sequence data indicates that the process may not be far enough along genetically, even though there appear to be some morphological and pathological differences. Similarly with $P$. ramorum, AFLP and DNA sequence data supports different populations of the same species (21). Brasier and Hansen (8) offer selection and reproductive isolation as two aspects of the speciation process in Phytophthora spp. that can be inferred from present evidence. With plant pathogens, the host plant can act as a genetic sieve that continues to select and separate populations. These gradual changes may not be observable at one point in time, and we would be hard pressed to determine if this is occurring within the $P$. capsici/P. tropicalis group without more information gathered over time. However, if this were found to be true through further research, then the temperate population of the species may have or may be evolving from the tropical population in terms of host specificity, morphological adaptations, and genetic composition.

The presented morphological and molecular data and the previously reported and referenced pathogenicity data $(4,22,30)$ may point in this direction, but will this process lead to reproductive isolation between temperate and tropical isolates? Morphological differences may only be an adaptation to the environment, and only represent different morphospecies $(16,19)$. Studies have shown that some morphospecies are composed of several biological species, phylogenetic species, or both (19). Only studies looking at crosses between and among populations of these two groups will answer the question as to whether the temperate and tropical isolates are conspecific or reflective of different recognized species.

A clearer picture of what level of sequence variation is reflective of variation within a species compared to between closely related species also is needed for the genus as a whole before the data can be used to draw conclusions about species classification of these isolates. Different regions of the genome also need to be sequenced and included in the phylogenetic analysis, and then compared with morphological and pathogenicity data from a wide variety of isolates before enough evidence can be gathered to firmly support the species designation of these isolates. Other authors have reported isolating an organism they called $P$. tropicalis based on available data $(15,20)$. We submit that the available data are incomplete, and that the full range of variation in the species has not yet been examined. Isolates identified as $P$. capsici or $P$. tropicalis may represent different subgroups in a broad continuum of variation that is presently called $P$. capsici. We, therefore, recommend refraining from using the epithet $P$. tropicalis for isolates more related to the tropical population of $P$. capsici until more data are available.

\section{ACKNOWLEDGMENTS}

We gratefully acknowledge the assistance of M. White (U.S. Department of Agriculture-Agricultural Research Service [ARS]), Beltsville, MD) in the AFLP and ITS sequence studies; R. Anacker (Maryland Department of Agriculture, Annapolis), in the ITS RFLP studies; and M. Carras (ARS, Ft. Detrick, MD) in the linear growth and chlamydospore production studies. We also thank M.-C. Bon (ARS, Montpelier, France) and J. Saunders (Towson University, Towson, MD) for their review of the manuscript. 


\section{LITERATURE CITED}

1. Alizadeh, A., and Tsao, P. H. 1985. Chlamydospore formation in 'Phytophthora palmivora' MF4. Trans. Br. Mycol. Soc. 85:71-79.

2. Alizadeh, A., and Tsao, P. H. 1985. Effect of light on sporangium formation, morphology, ontogeny, and caducity of Phytophthora capsici and 'P. palmivora' MF4 isolates from black pepper and other hosts. Trans. Br. Mycol. Soc. 85:47-69.

3. Aragaki, M., and Uchida, J. Y. 1992. Recent findings in Phytophthora capsici / P. tropicalis complex. (Abstr.) Phytopathology 82:1164.

4. Aragaki, M., and Uchida, J. Y. 2001. Morphological distinctions between Phytophthora capsici and P. tropicalis sp. nov. Mycologia 93:137-145.

5. Ayers, W. A., and Lumsden, R. D. 1975. Factors affecting production and germination of oospores of three Pythium species. Phytopathology 65:1094-1100.

6. Baker, K. F., and Cook, R. G. 1974. Biological Control of Plant Pathogens. W. H. Freeman and Co., San Francisco.

7. Brasier, C. M., and Griffin, M. J. 1979. Taxonomy of 'Phytophthora palmivora' on cocoa. Trans. Br. Mycol. Soc. 72:111-143.

8. Brasier, C. M., and Hansen, E. M. 1992. Evolutionary biology of Phytophthora. Annu. Rev. Phytopathol. 30:173-200.

9. Cooke, D. E. L., Drenth, A., Duncan, J. M., Wagels, G., and Brasier, C. M. 2000. A molecular phylogeny of Phytophthora and related oomycetes. Fungal Genet. Biol. 30:17-32.

10. Cooke, D. E. L., and Duncan, J. M. 1997. Phylogenetic analysis of Phytophthora species based on ITS1 and ITS2 sequences of the ribosomal RNA gene repeat. Mycol. Res. 101:667-677.

11. Cooke, D. E. L., Duncan, J. M., Williams, N. A., Hagenaar-de Weerdt, M., and Bonants, P. J. M. 2000. Identification of Phytophthora species on the basis of restriction enzyme fragment analysis of the internal transcribed spacer regions of ribosomal RNA. Bulletin OEPP/ Energy Planning and Policy Office (EPPO) Bull. 30:519-523.

12. de Souza, J. T., Pomella, A. W. V., Bowers, J. H., Pirovani, C. P., Loguercio, L. L., and Hebbar, K. P. 2006. Genetic and biological diversity of Trichoderma stromaticum, a mycoparasite of the cacao witches' broom pathogen. Phytopathology 96:61-67.

13. Erwin, D. C., and Ribeiro, O. K. 1996. Phytophthora Diseases Worldwide. The American Phytopathological Society, St. Paul, MN.

14. Förster, H., and Coffey, M. D. 1990. Mating behavior of Phytophthora parasitica: evidence for sexual recombination in oospores using DNA restriction fragment length polymorphisms as genetic markers. Exp. Mycol. 14:351-359.

15. Gerlach, W. W. P., and Schubert, R. 2001. A new wilt of cyclamen caused by Phytophthora tropicalis in Germany and the Netherlands. Plant Dis. $85: 334$.

16. Glawe, D. A. 2003. Much more than phylogenies: a utilitarian view of the taxonomy of plant pathogenic fungi. Published online by The American Phytopathological Society.

17. Griffin, M. J. 1977. Cocoa Phytophthora Workshop. Rothamsted Experimental Station, Eng. 1976. PANS 23:107-110.

18. Hampl, V., Pavlicek, A., and Flegr, J. 2001. Construction and bootstrap analysis of DNA fingerprinting-based phylogenetic trees with the freeware program FreeTree: application to trichomonad parasites. Int. J. Syst. Evol. Micrbiol. 51:731-735.

19. Hawksworth, D. L., Kirk, P. M., Sutton, B. C., and Pegler. D. N. 1995. Page 427 in: Ainsworth \& Bisby's Dictionary of the Fungi. CAB Int., Wallingford, UK.

20. Hong, C. X., Richardson, P. A., and Kong, P. 2006. Phytophthora tropicalis isolated from diseased leaves of Pieris japonica and Rhododendron catawbiense and found in irrigation water and soil in Virginia. Plant Dis. 90:525.

21. Ivors, K. L., Hayden, K. J., Bonants, J. M., Rizzo, D. M., and Garbelotto, M. 2004. AFLP and phylogenetic analyses of North American and European populations of Phytophthora ramorum. Mycol. Res. 108:378-392.

22. Kellam, M. K., and Zentmyer, G. A. 1986. Morphological, physiological, ecological, and pathological comparisons of Phytophthora species isolated from Theobroma cacao. Phytopathology 76:159-164.

23. Kommedahl, T., and Windels, C. E. 1981. Introduction of microbial antagonists to specific courts of infection: seeds, seedlings, and wounds. Pages 227-248 in: Biological Control in Crop Protection, Beltsville Symposia in Agricultural Research, 5. G. C. Papavizas, ed. Allanheld, Osmun Publishers, Granada.

24. Kong, P., Hong, C., Richardson, P. A., and Gallegly, M. E. 2003. Singlestrand-conformation polymorphism of ribosomal DNA for rapid species differentiation in genus Phytophthora. Fungal Genet. Biol. 39:238-249.
25. Lamour, K. H., and Hausbeck, M. K. 2000. Mefenoxam insensitivity and the sexual stage of Phytophthora capsici in Michigan cucurbit fields. Phytopathology 90:396-400.

26. Lamour, K. H., and Hausbeck, M. K. 2001. Investigating the spatiotemporal genetic structure of Phytophthora capsici in Michigan. Phytopathology 91:973-980.

27. Lamour, K. H., and Hausbeck, M. K. 2002. The spatiotemporal genetic structure of Phytophthora capsici in Michigan and implications for disease management. Phytopathology 92:681-684.

28. Lamour, K. H., and Hausbeck, M. K. 2004. Phytophthora capsici on vegetable crops: research progress and management challenges. Plant Dis. 88:1292-1303.

29. Leonian, L. H. 1922. Stem and fruit blight of peppers caused by Phytophthora capsici sp. nov. Phytopathology 12:401-408.

30. Luz, E., Cerqueira, A., Bowers, J., and De Souza, J. 2006. Polyphasic taxonomic analysis of Phytophthora capsici. (Abstr.) Phytopathology 96:S71.

31. Martin, F.N. 1995. Meiotic instability of Pythium sylvaticum as demonstrated by inheritance of nuclear markers and karyotype analysis. Genetics 139:1233-1246.

32. Martin, F. N. 2000. Phylogenetic relationships among some Pythium species inferred from sequence analysis of the mitochondrially encoded cytochrome oxidase II gene. Mycologia 92:711-727.

33. Martin, F. N., and Tooley, P. W. 2003. Phylogenetic relationships among Phytophthora species inferred from sequence analysis of mitochondrially encoded cytochrome oxidase I and II genes. Mycologia 95:269-284.

34. Martin, F. N., and Tooley, P. W. 2004. Identification of Phytophthora isolates to species level using restriction fragment length polymorphism analysis of a polymerase chain reaction-amplified region of mitochondrial DNA. Phytopathology 94:983-991.

35. Mayer, E. 1963. Animal Species and Evolution. Harvard University Press. Cambridge, MA.

36. Mchau, G. R. A., and Coffey, M. D. 1995. Evidence for the existence of two subpopulations in Phytophthora capsici and a redescription of the species. Mycol. Res. 99:89-102.

37. Oudemans, P., and Coffey, M. D. 1991. A revised systematics of twelve papillate Phytophthora species based on isozyme analysis. Mycol. Res. 95:1025-1046.

38. Page, R. D. M. 1996. TREEVIEW: An application to display phylogenetic trees on personal computers. Comp. Appl. Biosci. 12:357-358.

39. Ristaino, J. B. 1990. Intraspecific variation among isolates of Phytophthora capsici from pepper and cucurbit fields in North Carolina. Phytopathology 80:1253-1259.

40. Ristaino, J. B., and Johnston, S. A. 1999. Ecologically based approaches to management of Phytophthora blight on bell pepper. Plant Dis. 83:10801089.

41. Silvar, C., Merino, F., and Diaz, J. 2006. Diversity of Phytophthora capsici in northwest Spain: Analysis of virulence, metalaxyl response, and molecular characterization. Plant Dis. 90:1135-1142.

42. Tsao, P. H. 1971. Chlamydospore formation in sporangium-free liquid cultures of Phytophthora parasitica. Phytopathology 61:1412-1413.

43. Tsao, P. H., and Alizadeh, A. 1988. Recent advances in the taxonomy and nomenclature of the so-called "Phytophthora palmivora" MF4 occurring on cocoa and other tropical crops. Pages 441-445 in: Proc. Int. Cocoa Res. Conf., 10th. 1987. Cocoa Producers Alliance, Hertford, Eng.

44. Tucker, C. M. 1931. Taxonomy of the genus Phytophthora De Bary. Missouri Agr. Exp. Sta. Bull. 153.

45. Uchida, J. Y., and Aragaki, M. 1985. Occurrence of chlamydospores in Phytophthora capsici. Mycologia 77:832-835.

46. Uchida, J. Y., and Aragaki, M. 1989. Comparison of pepper isolates of Phytophthora capsici from New Mexico to other solanaceous and nonsolanaceous isolates. (Abstr.) Phytopathology 79:1212.

47. White, T. J., Bruns, T., Lee, S., and Taylor, J. 1990. Amplification and direct sequencing of fungal ribosomal RNA genes for phylogenetics. Pages 315-322 in: PCR Protocols: A Guide to Methods and Applications. M. A. Innis, D. H. Gelfand, J. J. Sninsky, and T. J. White, eds. Academic Press, Inc., San Diego, CA.

48. Zentmyer, G. A., Kaosiri, T., Idosu, G., and Kellam, M. K. 1981. Morphological forms of Phytophthora palmivora. Pages 291-295 in: Proc. Int. Cocoa Res. Conf., 7th. 1979. M. Laliberte, ed. Transla-Inter Ltd., London.

49. Zhang, Z. G., Zhang, J. Y., Zheng, X. B., Yang, Y. W., and Ko, W. H. 2004. Molecular distinctions between Phytophthora capsici and Ph. tropicalis based on ITS sequences of ribosomal DNA. J. Phytopathol. 152:358-364. 